\title{
ORIGINAL ARTICLE \\ Daily profiles of energy and nutrient intakes: are eating profiles changing over time?
}

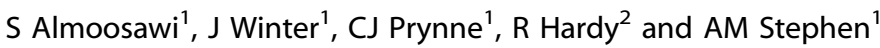

BACKGROUND/OBJECTIVES: Associations between timing of eating occasions and their nutrient composition and health have been described in interventional and cross-sectional studies. However, data from longitudinal data are limited. This study examined 17-year changes in energy and macronutrient intake across eating occasions in the 1946 British birth cohort. SUBJECTS/METHODS: Data were obtained from the 1946 British birth cohort. Cohort members completed 5d-estimated diaries at ages 36 (1982), 43 (1989) and 53 years (1999). Data from subjects who provided dietary data at all three time points were analysed $(n=1253)$. Repeated-measures analysis of variance with post hoc Bonferroni's adjustment was used to examine changes in energy and macronutrient at breakfast, mid-morning, lunch, mid-afternoon, evening and extra meal slots between 1982 and 1999. Analyses were stratified by sex and social class.

RESULTS: The proportion of energy and macronutrients consumed at lunch declined between 1982 and 1999, which was compensated by a greater intake in the mid-afternoon and evening. This trend was seen across sex and social class, although women and adults with a non-manual occupation reported greater energy, carbohydrate and non-starch polysaccharide intake at breakfast in 1982 and had a higher protein intake in the evening compared with men and adults with a manual occupation. CONCLUSIONS: The timing of energy and nutrient intake has shifted slightly over time, with a greater proportion of intake later in the day. The association between the observed sex and occupational social class differences in eating profiles and chronic disease warrants investigation.

European Journal of Clinical Nutrition (2012) 66, 678-686; doi:10.1038/ejcn.2011.210; published online 21 December 2011

Keywords: energy distribution; macronutrient distribution; circadian rhythm; eating profile; NSHD

\section{INTRODUCTION}

To date, most nutritional research has focused on studying the foods and nutrients consumed in the diet, the factors that influence their intake, and their impact on health and disease. Recently, there has been a move towards exploring patterns of food consumption, such as the frequency of eating and the timing of consumption during the day. ${ }^{1}$ Associations between breakfast skipping, late night eating and obesity are described in crosssectional ${ }^{2,3}$ and longitudinal studies. ${ }^{4-8}$ The time and nutrient composition of a meal has also been shown to induce insulin resistance, hypertriglyceridemia and leptinemia in animals. ${ }^{9}$ De Castro ${ }^{10-13}$ has indicated that the distribution of energy influences total daily energy intake over the day, and that the time and macronutrient composition of a meal produces nutrientspecific changes in intake, such that greater consumption of carbohydrate at breakfast is associated with lower energy and carbohydrate intake over the day whereas greater intake in the evening is associated with higher daily energy and macronutrient intake. ${ }^{11}$ Consistent with this, individuals consuming highcarbohydrate and high-fibre breakfasts have lower daily energy intake and lower BMl compared with those eating high-protein breakfasts. ${ }^{14}$

To date few recommendations exist for the appropriate distribution of intake of energy across the day ${ }^{15,16}$ and there is limited research describing the distribution of energy and macronutrient on a population level. ${ }^{17,18}$ Moreover, although there is a general belief that eating patterns have changed in recent decades, there is little information on changes in the distribution of energy and nutrient intake over time.

The present study aimed to describe the distribution of energy and macronutrient intake across different eating occasions and to assess long-term changes in energy and macronutrient intake over two decades in the 1946 British birth cohort.

\section{METHODS}

\section{Study population}

The Medical Research Council (MRC) National Survey of Health and Development (NSHD), or the 1946 British birth cohort, is a social classstratified longitudinal study of a random sample of 2815 men and 2547 women born in England, Scotland and Wales during the first week of March 1946. Cohort members were followed through their lifecourse and information on health, lifestyle, social background and various other aspects were collected at twenty-one occasions through a variety of interview methods. Dietary data were collected at age 4 years and three times in adulthood, at ages 36 (1982), 43 (1989) and 53 years (1999). Adult dietary assessment was achieved through completion of $5 \mathrm{~d}$-estimated diaries. By 1982 (age 36 years), 3322 were still actively participating in the survey with 323, 644, 520 and 553 cohort members being lost due to death, emigration, refusal and failure to trace, respectively. Of these,

${ }^{1}$ MRC Human Nutrition Research, Elsie Widdowson Laboratory, Cambridge, UK and ${ }^{2}$ MRC Unit for Lifelong Health and Ageing, London, UK. Correspondence: Dr S Almoosawi, MRC Human Nutrition Research, Elsie Widdowson Laboratory, 120 Fulbourn Road, CB1 9NL Cambridge, UK.

E-mail: suzana.almoosawi@mrc-hnr.cam.ac.uk

Contributors: SA contributed to the study design, data analysis, data interpretation and manuscript preparation. JW contributed to the initial input on study design, data analysis and interpretation. CJP provided guidance on data analyses and reviewed the manuscript. AMS and RH contributed to conceptualization of the study question, data interpretation and reviewing the manuscript.

Received 31 March 2011; revised 8 November 2011; accepted 9 November 2011; published online 21 December 2011 


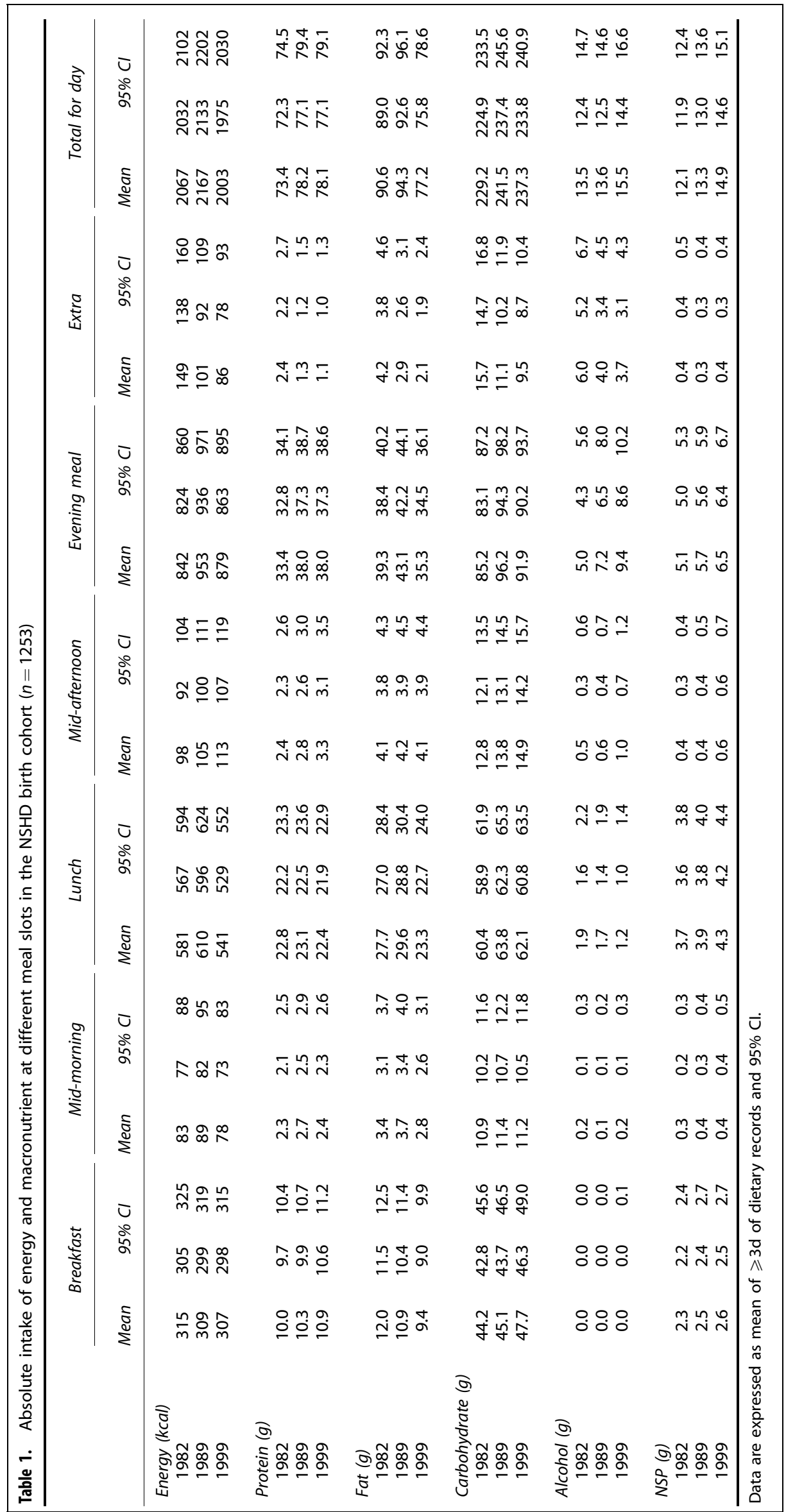


1253 cohort members (562 men and 691 women) provided at least 3d of dietary record at all three adult time points collected so far and are the sample used in the present analysis. Ethical approval was obtained from the Multicentre Research Ethics Committee.

\section{Dietary assessment}

Details of subject characteristics and dietary assessment have been described elsewhere. ${ }^{19}$ Briefly, cohort members were interviewed by research nurses at ages 36 (1982), 43 (1989) and 53 years (1999). Detailed instructions on how to complete the 5 d-estimated diet diaries were given by the nurses on each occasion. Guidance notes were provided at the beginning of each diary to assist subjects in describing portion sizes using household measures; photographs were introduced in 1989 to assist portion-size estimation.
Cohort members were instructed to record all food and drinks consumed both at home and away. In 1982, diet diaries were divided into six time slots: pre-breakfast, breakfast, mid-morning, lunch, midafternoon and evening. An additional time slot labelled 'extra' was made available for foods consumed through the day but not reported in previous time slots. In 1989 and 1999, the evening meal time slot was further divided into 'dinner' and 'up to last thing in the evening'. For the purpose of the present analysis, data from the latter two time slots were combined into one meal slot 'evening' to enable comparison with dietary data in 1982. However, additional analyses excluding data from 1982 were also performed to determine any differences in energy and macronutrient intake between 1989 and 1999 in the 'dinner' and 'up to last thing in the evening' time slots. A decision was made to combine the pre-breakfast and breakfast time-slots as only $3 \%$ of the population reported eating
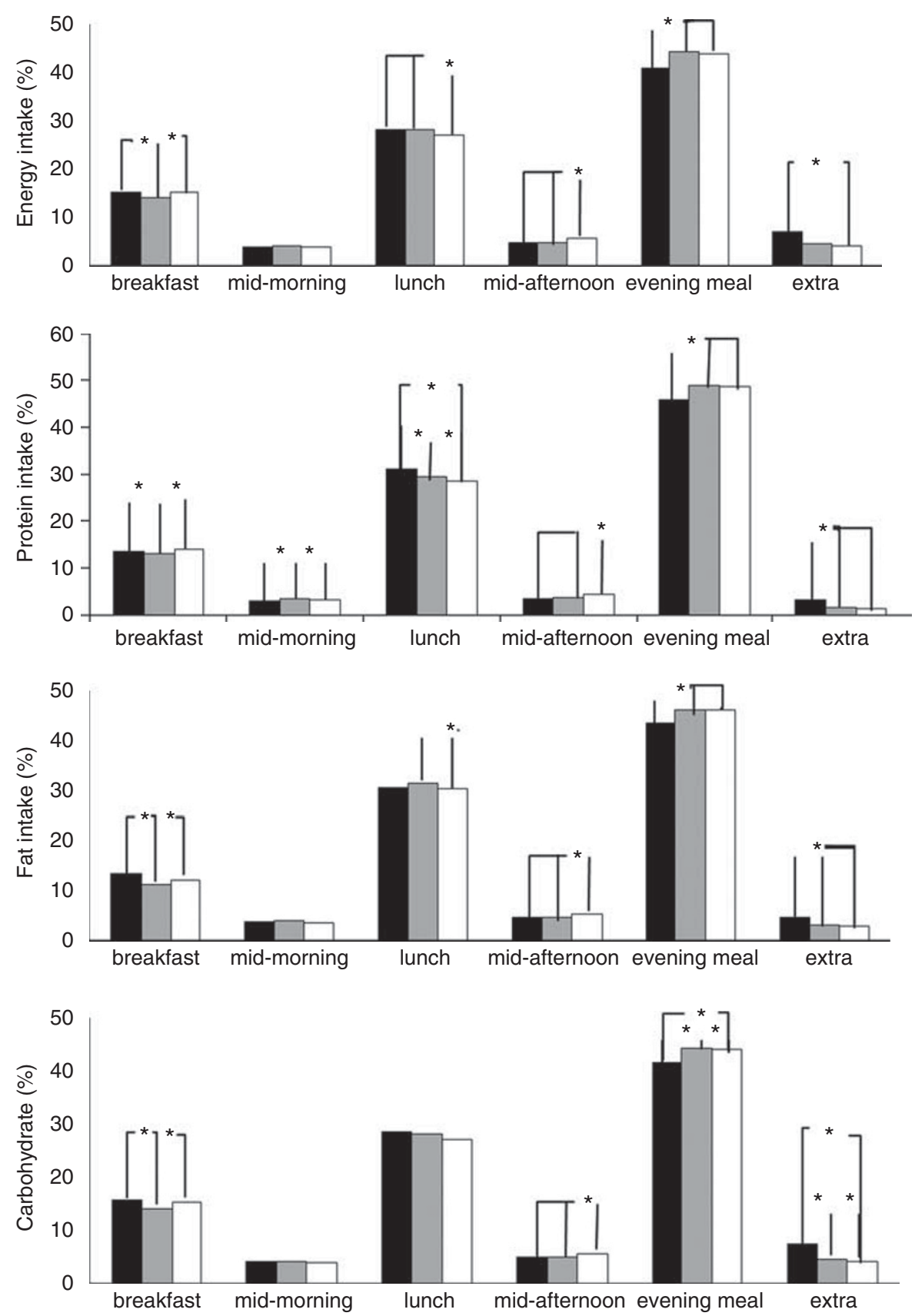

Figure 1. Secular changes in proportion of energy, protein, fat and carbohydrate intake at breakfast, mid-morning, lunch, mid-afternoon, evening and extra time slots in NSHD cohort $(n=1253) .{ }^{*}$ denotes statistical significance between the different survey years $(P<0.05)$. $1982(\square), 1989(\square)$ and $1999(\square)$. 
$>100 \mathrm{kcal}$ during the pre-breakfast period. Diet diaries were coded using the in-house programme Diet In Data Out (DIDO). ${ }^{20}$ Nutrient analysis were performed using the in-house suite of programs based on McCance and Widdowson's The Composition of Foods, taking into account food composition and portion sizes appropriate to the period of consumption. ${ }^{21-23}$

\section{Occupational social class}

The occupational social class of cohort members at 53 years was used as a marker of socioeconomic position, and was classified according to the Registrar General (1980) as either non-manual (managerial, professional, skilled professional ancillaries and service providers) or manual (skilled, non-skilled and agricultural workers). ${ }^{24}$

\section{Statistical analysis}

Mean energy and macronutrient intake for each of the six time slots in each of the 3-assessment years was calculated together with the $95 \%$ confidence intervals. Repeated-measures analysis of variance with post hoc Bonferroni's adjustment were used to examine changes in energy and macronutrient distribution between 1982 and 1999. Because absolute intakes of energy and macronutrients at a particular time slot depend on overall daily intake, all data were expressed as proportions of daily intake. ${ }^{11}$ Differences in energy and macronutrient distributions in 1982 between men and women and between adults with a manual or non-manual occupation were examined using an independent sample $t$-test. A mixed between-within subjects analysis of variance was also used to investigate changes in energy and macronutrient distribution at each time slot between 1982 and 1999 with sex or social class as a between-subject factor. Because significant year-by-sex and year-by-social class interactions were observed at some time slots, sex and social class stratified analyses were also performed. To establish whether there were differences in energy and macronutrients trends between weekdays and weekends, additional sensitivity analyses were conducted in which year-by-day of the week interactions were included in linear mixed models. We also ran analyses by including year-by-compliance interactions to examine whether there were differences in energy and nutrient trends between survey members who completed dietary assessment at all survey years and those who provided data at only one or two dietary assessment points.
This sensitivity analysis was performed to account for the possibility that cohort members who completed dietary assessment at all time points might be more compliant. Significant interactions would suggest that the findings might have arisen as a result of including data from a more compliant sample of the population. All data were analysed using Predictive Analytics SoftWare version 18 (SPSS Inc., Chicago, IL, USA). Significance level was set at $P<0.05$.

\section{RESULTS}

Changes in energy and macronutrient distribution over the day and survey years in the NSHD birth cohort

The distribution of energy and macronutrients varied considerably through the day in each of the survey years (Table 1).

Lunch and evening meals were found to contribute the greatest proportion of daily energy and macronutrient intake compared with other meal slots (Figures 1 and 2). The daily distribution of energy and macronutrients changed from 1982 through 1999. The proportion of daily energy, fat, protein and carbohydrate consumed at breakfast decreased between 1982 and 1989, but then returned to similar levels to 1982 between 1989 and 1999. Non-starch polysaccharides (NSP) intake decreased between 1989 and 1999. Lunch had a lower contribution to overall daily intake of energy, protein, alcohol and NSP in 1999 compared with 1982. However, the contribution of lunch to daily fat intake was higher in 1989 compared with 1999. A shift towards greater energy and macronutrient intake in mid-afternoon and evening was observed in 1989 and 1999 compared with 1982. Evening alcohol intake, in particular, increased from $36 \%$ of total daily intake in 1982 to $63 \%$ in 1999. Between 1989 and 1999, this rise in proportion of evening alcohol consumed occurred as a result of an increase in the proportion of alcohol consumed at dinner from $30.5 \%(95 \% \mathrm{Cl}$, $28.0-33.0)$ to $38.6 \%(95 \% \mathrm{Cl}, 36.3-75.1)(P<0.001)$. Separate analysis of the 'dinner' and 'up to last thing in the evening' time slots demonstrated no differences in energy intake at 'dinner' and 'up to last thing in the evening' between 1989 and 1999, and no changes in protein and carbohydrate intake at 'up to last thing in the evening' (data not shown) implying that most of the shift in energy and macronutrient intake towards the evening occurred
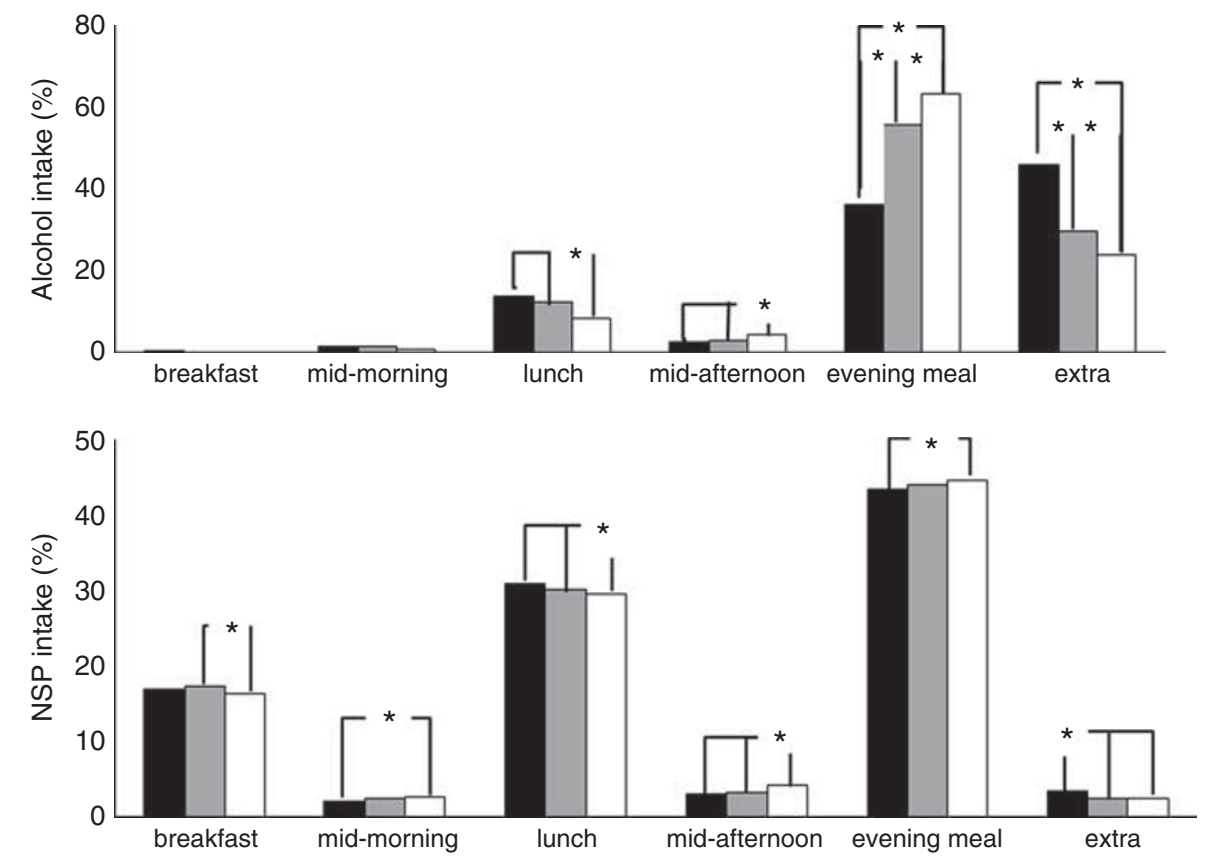

Figure 2. Secular changes in proportion of alcohol and NSP intake at breakfast, mid-morning, lunch, mid-afternoon, evening and extra time slots in NSHD cohort $(n=1253)$. * denotes statistical significance between the different survey years $(P<0.05) .1982(\square), 1989(\square)$ and $1999(\square)$. 
between 1982 and 1989. No significant interactions between survey year and day-of-the-week were observed suggesting that changes in energy and macronutrient distribution were similar between weekdays and weekends (data not shown). Similarly, no significant interactions between survey year and compliance were observed (data not shown) suggesting that trends in the distribution of energy and macronutrients changed to a similar extent between 1982 and 1999 in survey members who provided data on one or two time points compared with survey members who completed dietary assessment at all time points.

Sex differences in energy and macronutrient distribution In 1982, women obtained a larger proportion of their energy, carbohydrate and NSP at breakfast compared with men who ingested a greater proportion of energy and macronutrients at lunch. Women also had a higher energy, fat and carbohydrate intake at mid-afternoon.

When changes in energy and macronutrient distribution between 1982 and 1999 were analysed according to sex, small but significant differences in energy and macronutrient distribution between men and women were observed at some meal slots. Repeated-measures analysis of variance with sex as the betweensubject factor revealed a significant effect of survey year and year-by-sex interaction on energy $(P$ for interaction $=0.005)$, carbohydrate $(P=0.013)$, protein $(P=0.018)$ and fat $(P=0.003)$ at breakfast and on protein intake at mid-morning $(P=0.013)$. Women showed a greater reduction in energy and macronutrient intake at breakfast between 1982 and 1989 with a subsequent greater increase between 1989 and 1999 compared with men
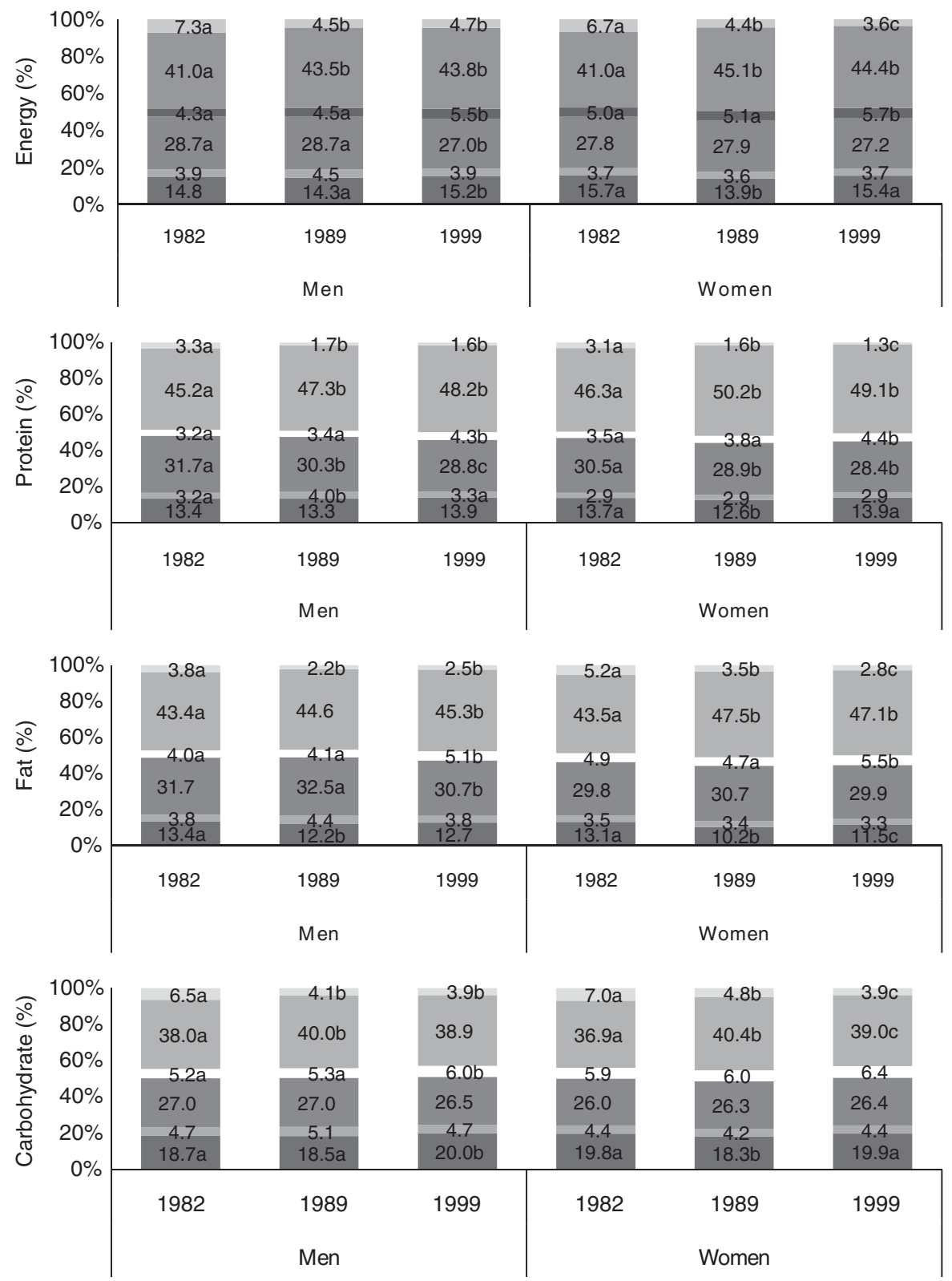

Figure 3. Secular changes in proportion of energy, protein, fat and carbohydrate intake at breakfast, mid-morning, lunch, mid-afternoon, evening and extra time slots in men and women. Corresponding meal slots with different letters $(a, b, c)$ indicate significant differences across the survey years. Meal slots with no letters are not significantly different from corresponding meal slots from other years. Extra $(\square)$, evening $(\square$ ), mid-afternoon $(\square)$, lunch $(\square)$, mid-morning ( $\square$ ) and breakfast $(\square)$. 
(Figure 3). Significant interactions were also observed for NSP intake at breakfast $(P<0.0001)$ and lunch $(P=0.001)$. Differences in protein intake between survey years and between men and women were also noted in the evening $(P=0.033)$. Women had a greater rise in protein intake between 1982 and 1989, which was followed by a decline in protein intake in 1999 compared with men who showed a progressive increase in protein intake between 1982 and 1999. Differences across the years in intake of energy and macronutrients were also observed at lunch and mid-afternoon. However, no year-by-sex interaction was seen suggesting that the change pattern was similar between men and women. Results of stratified analyses are presented in Figures 3 and 4.

Social class differences in energy and macronutrient distribution Compared with adults with a non-manual occupation, adults with a manual occupation consumed a lower proportion of energy, protein, carbohydrate and NSP at breakfast in 1982. They also had a lower alcohol intake at dinner although they reported a greater proportion of alcohol intake and other macronutrients within the extra slot. Adults with a non-manual occupation had a higher energy and fat intake in the evening in 1982 and a lower NSP intake.

There was a significant effect of year and year-by-social class interaction on energy $(P=0.002)$, protein $(P=0.003)$, fat $(P=0.017)$ and NSP intake $(P<0.0001)$ at breakfast and on energy $(P=0.004)$, protein $(P=0.001)$, fat $(P=0.030)$ and NSP intake $(P=0.008)$ at lunch. The decline in energy, protein and fat intake at breakfast in 1989 was greater in the non-manual group but the rise in intake of these nutrients between 1989 and 1999 was greater in the manual group (Figure 5). Intake of NSP decreased progressively in the non-manual group compared with the manual group where the rise in NSP intake in 1989 was followed by a decline in 1999 (Figure 6). At mid-afternoon, year-by-social class interactions were observed for energy $(P=0.018)$, protein $(P=0.001)$ and fat $(P=0.038)$, the values for which increased to a greater extent in the manual group. Within the extra time slot, a larger decline in the proportion of energy intake was seen in the manual group compared with non-manual group (year-social class interaction $P=0.046$ ). Results of stratified analyses are presented in Figures 5 and 6 .

\section{DISCUSSION}

The present study demonstrates that energy and macronutrient intake vary through the day and that over the two decades the distribution of energy and macronutrient intake has shifted slightly towards the mid-afternoon and evening. The greater contribution of lunch and evening meals to total daily energy and macronutrient intake is consistent with the work of de Castro, ${ }^{11}$ who showed that energy intake increases progressively through the day. This effect could be attributed to the gradual increase in meal size over the day ${ }^{10,11}$ possibly because of reduced satiety. ${ }^{10}$ However, to our knowledge, no studies have as yet described prospective changes in both energy and macronutrient distribution, although changes in the prevalence of breakfast skipping and late night eating have been reported in children ${ }^{25,26}$ and adults. ${ }^{27}$ Our findings are in agreement with the greater evening energy intake reported in the United States and Dutch student populations but not in the French. ${ }^{11}$ In the latter population both lunch and evening meals contribute equally to daily energy intake, ${ }^{28}$ highlighting cultural and social factors as potential determinants of energy and macronutrient distribution. Changes in temporal distribution of eating occasions, snacking, breakfast skipping, night-eating and frequency of meals eaten away from home have been reported in countries experiencing rapid social

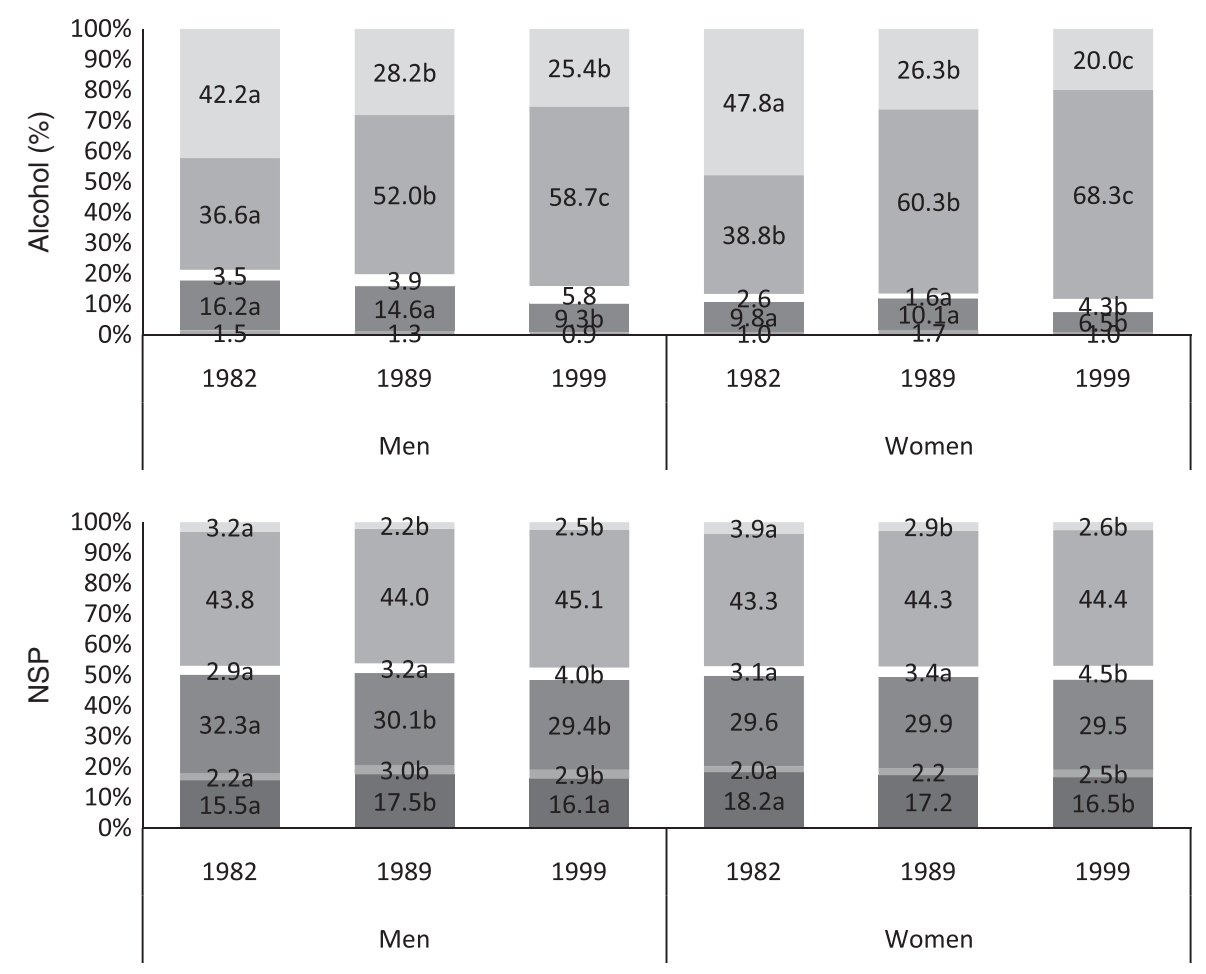

Figure 4. Secular changes in proportion of alcohol and NSP intake at breakfast, mid-morning, lunch, mid-afternoon, evening and extra time slots in men and women. Corresponding meal slots with different letters $(a, b, c)$ indicate significant differences across the survey years. Meal slots with no letters are not significantly different from corresponding meal slots from other years. Extra $(\square)$, evening $(\square)$, mid-afternoon $(\square)$, lunch $(\square)$, mid-morning $(\square)$ and breakfast $(\square)$. 
and economic transition. ${ }^{29-31}$ In working Korean adults, a trend of breakfast skipping, eating away from home and snacking on energy-dense foods in the evening has been described. ${ }^{31}$ Likewise, Thomas ${ }^{32}$ indicated variations in the frequency of breakfast skipping on weekdays compared with weekends and employed versus unemployed British women. Thomas ${ }^{32}$ also observed that the social context of a meal determines the size of meals, with lunch being perceived as a snack eaten away from home amongst working British adults and dinner being viewed as a large social event bringing family members together. ${ }^{32}$ It could, thus, be hypothesised that longer working hours, time scarcity, social commitments, changing family structures and greater availability of foods ${ }^{33}$ may all have contributed to the changing trends seen in energy and macronutrient distribution in the current analysis.
Absolute intake of fat (grams per day), and to a lesser extent the proportion of fat, declined progressively at breakfast between 1982 and 1999. Previous NSHD analyses have reported a reduction in the percentage energy from fat from $38.5 \%$ in 1982 to $34.4 \%$ in $1999 .^{19}$ This was attributed to a reduction in fat content of meat and meat products, such as bacon and ham, as a result of improved butchery methods, animal feeds and selective breeding. ${ }^{19}$ Although lower fat content of ham and bacon may have contributed to the lower fat intake at breakfast, decreased consumption of cooked breakfast, cakes and biscuits ${ }^{34}$ and the shift in consumer preference towards low-fat milk and spreads are more likely to explain these findings. ${ }^{35}$ Analysis of secular changes in consumption of specific foods may explain our findings further but was beyond the scope of the current investigation of nutrients.
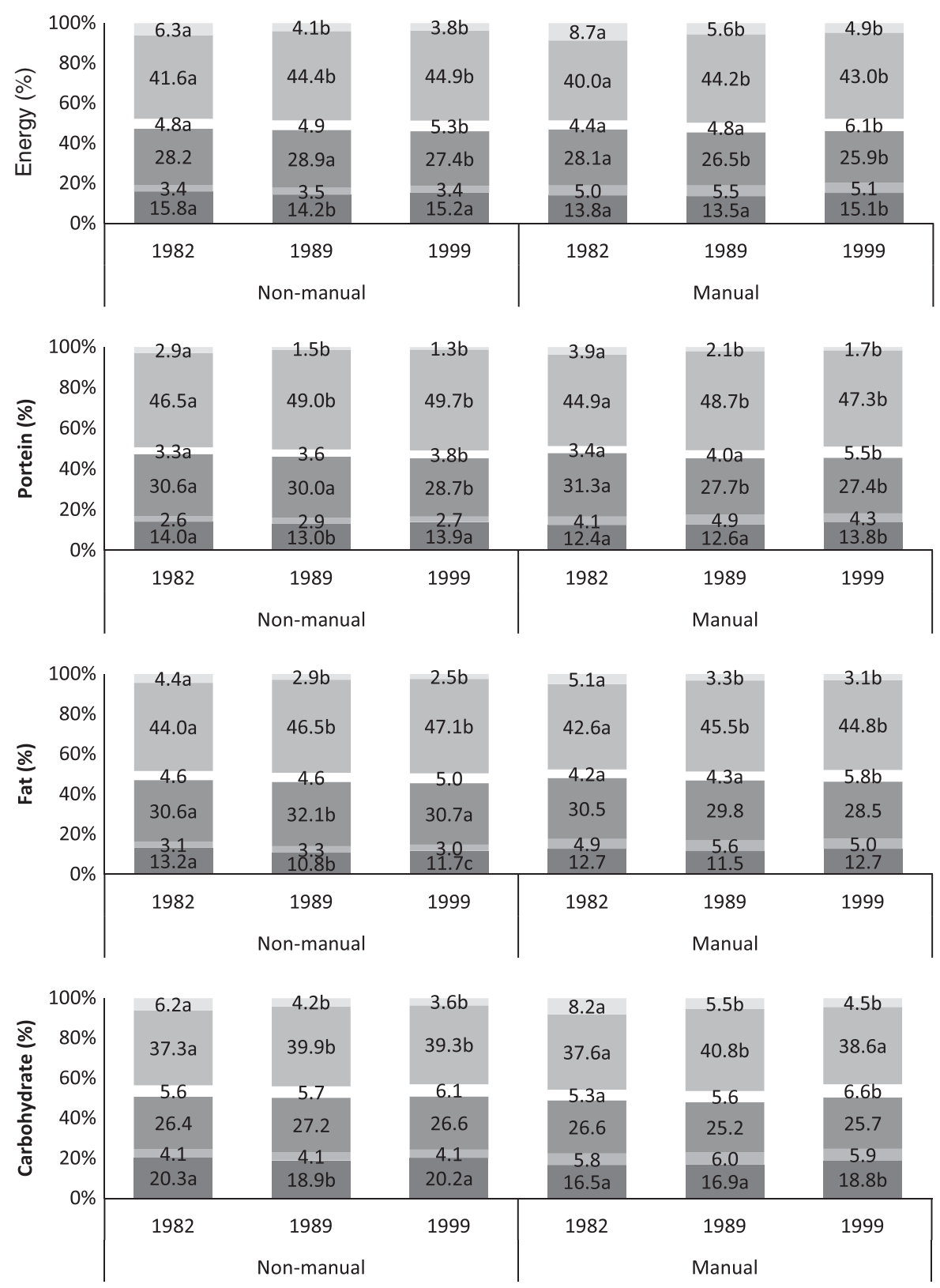

Figure 5. Secular changes in proportion of energy, protein, fat and carbohydrate intake at breakfast, mid-morning, lunch, mid-afternoon, evening and extra time slots in adults with a non-manual and manual occupation. Corresponding meal slots with different letters ( $a$, b, c) indicate significant differences across the survey years. Meal slots with no letters are not significantly different from corresponding meal slots from other years. Extra $(\square)$, evening $(\square)$, mid-afternoon $(\square$ ), lunch ( $\square$ ), mid-morning $(\square)$ and breakfast $(\square)$. 


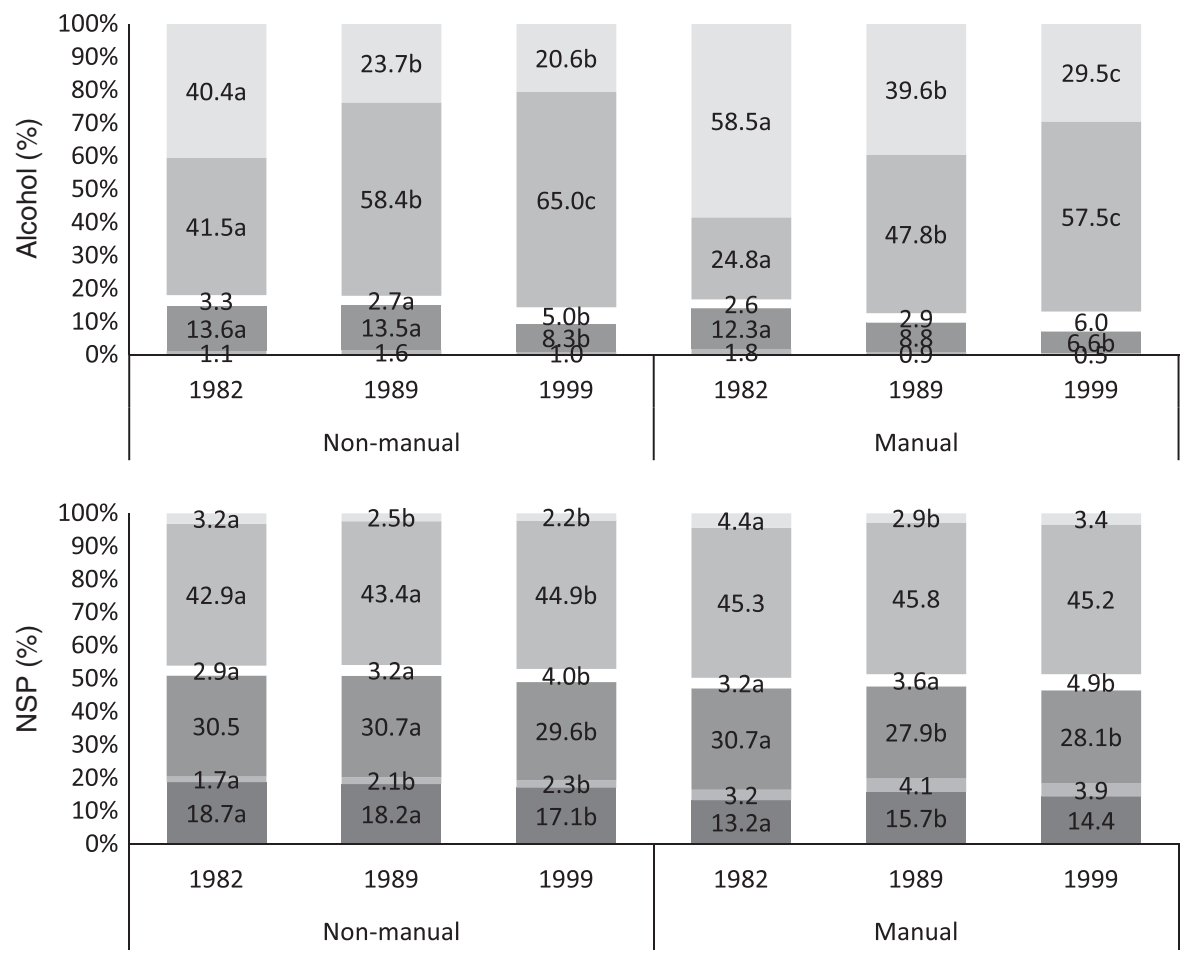

Figure 6. Secular changes in proportion of alcohol and non-starch polysaccharides intake at breakfast, mid-morning, lunch, mid-afternoon, evening and extra time slots in adults with a non-manual and manual occupation. Corresponding meal slots with different letters (a, b, $c$ ) indicate significant differences across the survey years. Meal slots with no letters are not significantly different from corresponding meal slots from other years. Extra $(\square)$, evening $(\square$ ), mid-afternoon $(\square)$, lunch $(\square)$, mid-morning $(\square)$ and breakfast $(\square$ ).

In the present analysis, the proportion of NSP intake at breakfast was lower in 1999 compared with 1989. However, absolute intakes were higher implying that the reduction in the proportion of NSP intake at breakfast is likely to have occurred as a result of greater NSP intake in mid-afternoon. Indeed, over time, energy and macronutrient intake shifted towards later in the day. This redistribution of macronutrient intake towards the evening may be detrimental to health. ${ }^{28,31,36}$ Evening eating is associated with various metabolic abnormalities and obese subjects exhibit a distinct eating pattern characterised by greater energy intake in the afternoon and evening. ${ }^{37}$ Together this evidence raises the question as to whether differences in energy and macronutrient distribution could account for variations in cardiometabolic risk factors across sex and socioeconomic position. Our analysis show that women ate a greater proportion of energy and NSP at breakfast in 1982 compared with men who had a greater intake of energy and macronutrient at lunch. Similarly, adults with a manual occupation reported lower energy intake at breakfast in 1982 compared with adults with a non-manual occupation. The pattern of change in eating profiles also varied across sex and socioeconomic position with social differences persisting over the years, possibly highlighting socioeconomic position as a stronger determinant of energy and macronutrient distribution than sex. Alternatively, changes in household composition between 1982 and 1999 with more women returning to work in 1999 as opposed to staying at home with children may have reduced sex differences. $^{38}$

There are several limitations to our findings. Differentiating secular trends from age effects is difficult in birth cohorts. ${ }^{18}$ The NSHD sample is exclusively white and does not include people from other ethnic groups, adults with a manual occupation are under-represented. ${ }^{39}$ The observed rise in energy and macronutrient intake in the evening may have arisen as an artefact of combining 'dinner' with 'up to last thing in the evening', particularly as most of the changes in intake were detected between 1982 and 1989. An inherent problem of the diet diaries used in NSHD is the inclusion of the 'extra' time slot. This slot could have biased recording, which could be supported by sex and socioeconomic differences in use of this time slot. It also remains unclear whether the observed reduction in the proportion of energy and macronutrients in the 'extra' slot over time has a risen as a consequence of the additional instructions for completion or the changing structure of the diet diaries in 1989 and 1999. Description of meals in the diet diaries was also subjective and not defined by time and the analyses did not control for under reporting. Finally, selection bias is a common problem in longitudinal studies as the nutrient intake of dropouts could be different from those who completed dietary assessment at all three time points. However, our results suggest that trends in energy and macronutrient distribution were similar between survey members who provided data at one or two dietary assessment points compared with those who completed dietary assessment at all time points.

The strengths of our analyses lie in the longitudinal design of NSHD and the rigour of the dietary assessment method, where dietary data collected is coded and calculated taking into account portion sizes common of the population time point assessed and using food composition databases appropriate for the period of consumption. Although changes in dietary coding, portion size estimation and nutrient databases have been viewed as limitations, ${ }^{19}$ the NSHD remains in many respects representative of the national population of a similar age $\mathrm{e}^{39}$ and trends in energy and nutrient intake are comparable between NSHD and National Diet and Nutrition Survey. ${ }^{40-42}$

In conclusion, the present study demonstrates that energy and macronutrient distribution varies through the day and that in recent years energy and macronutrient intake has shifted towards later in the day. The implications of such changes to long-term risk of obesity and cardiovascular disease remain to be determined. 


\section{CONFLICT OF INTEREST}

The authors declare no conflict of interest.

\section{ACKNOWLEDGEMENTS}

This work was supported by the UK National Prevention Research Initiative and the UK Medical Research Council (G701939).

\section{REFERENCES}

1 McCrory MA, Campbell WW. Effects of eating frequency, snacking, and breakfast skipping on energy regulation: symposium overview. J Nutr 2011; 141, 144 - 147

2 De La Hunty A, Ashwell M. Are people who regularly eat breakfast cereals slimmer than those who don't? A systematic review of the evidence. Nutr Bull 2007; 32, $118-128$.

3 Szajewska H, Ruszczynski M. Systematic review demonstrating that breakfast consumption influences body weight outcomes in children and adolescents in Europe. Crit Rev Food Sci Nutr 2010; 50, 113-119.

4 Purslow LR, Sandhu MS, Forouhi N, Young EH, Luben RN, Welch AA et al. Intake at breakfast and weight change: prospective study of 6764 middle-aged men and women. Am J Epidemiol 2008; 167, 188 - 192.

5 Berkey CS, Rockett HR, Gillman MW, Field AE, Colditz GA. Longitudinal study of skipping breakfast and weight change in adolescents. Int J Obes Relat Metab Disord 2003; 27, $1258-1266$.

6 Bellisle F, Rolland-Cachera MF, Deheeger M, Guilloud-Bataille M. Obesity and food intake in children: evidence for a role of metabolic and/or behavioral daily rhythms. Appetite 1988; 11, $111-118$.

7 Barton BA, Eldridge AL, Thompson D, Affenito SG, Striegel-Moore RH, Franko DL et al. The relationship of breakfast and cereal consumption to nutrient intake and body mass index: the National Heart, Lung, and Blood Institute Growth and Health Study. J Am Diet Assoc 2005; 105, $1383-1389$.

8 Albertson AM, Franko DL, Thompson D, Eldridge AL, Holschuh N, Affenito SG et al. Longitudinal patterns of breakfast eating in black and white adolescent girls. Obesity (Silver Spring) 2007; 15, $2282-2292$.

9 Bray MS, Tsai JY, Villegas-Montoya C, Boland BB, Blasier Z, Egbejimi O et al. Time-of-day-dependent dietary fat consumption influences multiple cardiometabolic syndrome parameters in mice. Int J Obes (Lond) 2010; 34, 1589- 1598.

10 de Castro JM. Circadian rhythms of the spontaneous meal pattern, macronutrient intake, and mood of humans. Physiol Behav 1987; 40, 437-446.

11 de Castro JM. The time of day of food intake influences overall intake in humans. J Nutr 2004; 134, 104-111.

12 de Castro JM, Bellisle F, Feunekes GIJ, Dalix AM, De Graaf C. Culture and meal patterns: A comparison of the food intake of free-living American, Dutch, and French students. Nutr Res 1997; 17, 807-829.

13 de Castro JM. The time of day and the proportions of macronutrients eaten are related to total daily food intake. Br J Nutr 2007; 98, 1077 - 1083.

14 Cho S, Dietrich M, Brown CJ, Clark CA, Block G. The effect of breakfast type on total daily energy intake and body mass index: results from the Third National Health and Nutrition Examination Survey (NHANES III). J Am Coll Nutr 2003; 22, 296-302.

15 Barbieri HE, Lindvall C. Swedish Nutrition Recommendations Objectified (SNO)- Basis for general advice on food consumption for healthy adults. Swedish National Food Administration: Uppsala, 2005.

16 Food Standard Agency Nutrient and Food Based Guidelines for UK Institutions 2007.

17 Samuelson G, Bratteby LE, Enghardt H, Hedgren M. Food habits and energy and nutrient intake in Swedish adolescents approaching the year 2000. Acta Paediatr Suppl 1996; 415, 1-19.

18 Matthys C, De Henauw S, Devos C, De Backer G. Estimated energy intake, macronutrient intake and meal pattern of Flemish adolescents. Eur J Clin Nutr 2003; 57, 366-375
19 Prynne CJ, Paul AA, Mishra GD, Greenberg DC, Wadsworth ME. Changes in intake of key nutrients over 17 years during adult life of a British birth cohort. Br J Nutr 2005; 94, 368-376.

20 Price GM, Paul AA, Key FB, Harter AC, Cole TJ, Day KC. Measurement of diet in a large national survey: comparison of computerised and manual coding in household measures. J Hum Nutr Diet 1995; 8, 417-428.

21 Paul AA, Southgate DAT. McCance and Widdowson's The Composition of Foods. HMSO: London, 1978

22 Holland B, Unwin ID, Buss DH, Cereals and Cereal Products: Third Supplement to McCance and Widdowson's The Composition of Foods. Royal Society of Chemistry and Ministry of Agriculture, Fisheries and Food: Nottingham, 1988.

23 Holland B, Unwin ID, Buss DH, Milk and Milk Products: Fourth Supplement to McCance and Widdowson's The Composition of Foods. Royal Society of Chemistry and Ministry of Agriculture, Fisheries and Food: Cambridge, 1989.

24 General R. Classification of Occupations. HMSO: London, 1980.

25 Siega-Riz AM, Popkin BM, Carson T. Trends in breakfast consumption for children in the United States from 1965-1991. Am J Clin Nutr 1998; 67, 748S-756S

26 Nicklas TA, Morales M, Linares A, Yang SJ, Baranowski T, De Moor C et al. Children's meal patterns have changed over a 21-year period: the Bogalusa Heart Study. J Am Diet Assoc 2004; 104, 753-761.

27 Haines PS, Guilkey DK, Popkin BM. Trends in breakfast consumption of US adults between 1965 and 1991. J Am Diet Assoc 1996; 96, 464-470.

28 Bellisle F, Dalix A, de Castro JM. Eating patterns in French subjects studied by the 'weekly food diary' method. Appetite 1999; 32, 46-52.

29 Adair LS, Popkin BM. Are child eating patterns being transformed globally. Obes Res 2005; 13, $1281-1299$.

30 Shi Z, Lien N, Kumar BN, Holmboe-Ottesen G. Socio-demographic differences in food habits and preferences of school adolescents in Jiangsu Province, China. Eur J Clin Nutr 2005; 59, 1439-1448.

$31 \mathrm{Kim}$ SY, Kim SM. Energy intake and snack choice by the meal patterns of employed people. Nutr Res Pract 2010; 4, 43-50.

32 Thomas JE. Food habits of the majority: evolution of the current UK pattern. Proc Nutr Soc 1982; 41, $211-228$.

33 Hill JO, Wyatt HR, Reed GW, Peters JC. Obesity and the environment: where do we go from here? Science 2003; 299, 853 -855.

34 Walker CL. The national diet. Postgrad Med J 1984; 60, 26-33.

35 Bates B, Lennox A, Swan G, National Diet and Nutrition Survey: Headline results from year 1 of the Rolling Programme (2008/09). Food standard agency and Department of Health: London, 2010.

36 Wahlqvist ML, Kouris-blazos A, Wattanapenpaiboon N. The significance of eating patterns: an elderly Greek case study. Appetite 1999; 32, 23 - 32.

37 Berteus Forslund H, Lindroos AK, Sjostrom L, Lissner L. Meal patterns and obesity in Swedish women-a simple instrument describing usual meal types, frequency and temporal distribution. Eur J Clin Nutr 2002; 56, 740-747.

38 Prynne CJ, Wadsworth MEJ, Mishra GD, Stephen AM. Household composition and individual diet; results from the National Survey of Health and Development 1982 and 1999. Longitudinal and life course studies. Longitudinal Life Course Stud 2010; 1, 239.

39 Wadsworth ME, Butterworth SL, Hardy RJ, Kuh DJ, Richards M, Langenberg C et al. The life course prospective design: an example of benefits and problems associated with study longevity. Soc Sci Med 2003; 57, 2193-2205.

40 Gregory J, Foster K, Tyler H, Wiseman M. The Diet and Nutritional Survey of British Adults. Office of Population Censuses and Surveys, Social Survey Division: London, 1990.

41 Henderson L, Irving K, Gregory J, Bates C, Prentice A, Perks J et al. The National Diet and Nutrition Survey: Adults Aged 19-64 years, vol 3 Vitamin and Mineral Intake and Urinary Analyses. The Stationery Office: London, 2003.

42 Henderson L, Gregory J, Irving K. The National Diet and Nutrition Survey: Adults Aged 19 to 64 Years. Vol. 2. Energy, Protein, Carbohydrate, Fat and Alcohol Intake. The Stationery Office: London, 2003.

This work is licensed under the Creative Commons AttributionNonCommercial-No Derivative Works 3.0 Unported License. To view a copy of this license, visit http://creativecommons.org/licenses/by-nc-nd/3.0/ 